\title{
The rehabilitation of the elderly in cognitive difficult: An integrated vision. Reality Orientation Therapy (R.O.T.) and the "caring" of relationship of diade elderly-care-giver.
}

\author{
Calabrese Cesare Maria*, Calabrese Marco Cesare, Calabrese Clelia Margherita
}

Punto R.O.T, Center for prevention and support of the elderly in cognitive difficulties, Italy

\begin{abstract}
In this article we try to give a new perspective of the possible areas of intervention with an elderly aected by dementia and his caregiver. With the increase in cases of the dementia, it becomes necessary to try new techniques for assistance of elderly and techniques that are able to slow down as much as possible the manifestation of psychiatric and behavioural symptoms. From our center in Genoa since 2011 to today we could try new ways to assist the couple elderly-caregiver, trying to promote the psycho-affective health of both. Reality Orientation Therapy (R.O.T. technique) and psycho-affective interventions are able to safeguard the couple caregiver-elderly and to slow the institutionalization in a nursing home. The elderly must be stimulated not only from the cognitive point of view but integrating emotional and relational aspect from environment in where he lives. From our clinical experience and from an examination of scientific literature we could assert that caring elderly's relationships and creating a profound relationship, with cognitive psycho-stimulation, the quality of elderly and caregiver life can be significantly improved.
\end{abstract}

Keywords: Dementia, Psychiatric and behavioural symptoms, Neuropsychological diseases, Clinical manifestations. Accepted date on September 05, 2018

\section{Introduction}

The improvement of the quality of life, a greater control on illnesses and a better attention on hygiene and on nutrition led to a lengthening of life in general population. To promote health and assistance in the aging process and an adequate rescue against neuropsychological diseases that can develop is important. We can mean the neuropsychological diseases as an alteration of the normal aging process, a process dicult in itself because of the physical and psychological changes.

With a larger number of seniors, diseases as dementia had increased. In 2016, they count 46.8 million people affected by dementia; 130 million cases are expected in 2030 [1]. Dementias are a very complex problem for psychologists and doctors because of the great heterogeneity in clinical manifestations. For a long time it is clear that we cannot have a univocal definition of what dementia is and what prognosis is necessary to define for each elderly. In this article we report our experience about the not-pharmacological treatment of dementias in a mild and moderate form, and generally, in that cases when cognitive abilities decreases. In our center we base our work on Reality Orientation Therapy (R.O.T.), brought in Italy by Florenzano, with other psycho-social and emotional treatments dedicated to care givers and elderly families. We can define R.O.T. Technique as a cognitive training to improve the ability of adaptation and orientation in the environment [2]. We do not use this technique in the strict sense, but we highlight the treatment as "psycho-stimulant" aimed at maximizing the cognitive and relational resources still present in the elderly [3-4]. There are many studies that highlight positive results to use this technique from the cognitive and behavioural point of view [5] that in some cases can give back the institutionalization of the elderly [6]. Another very important aspect is the relationship that is created between elderly and caregiver. Since a long ago it is known that caregiving in the long term involves stress, physical deteriorations, social isolation, decrease in personal time [7], but also emotional exhaustion, reduced personal fulfilment, sometimes depersonalization, when the caregiver lives his assistance without rest [8]. With the term "caregiver" we do not mean a specific professional figure, but a person who establishes a significant relationship of support and care with the elderly.

What to do with this relationship? Some academics, like us, think that this relationship can influence the course of disease, that is relieve the behavioural symptoms, and, generally, to increase relational skills [9]. We must not forget the centrality of the person, even if aected by dementia, who researches relationships and suers because of his condition [10].

The figure of caregiver faces numerous problems in the relationship with the elderly, also for the qualitative functions of the mind that are involved in dementia. With the continuation of disease, the elderly can have problems with the perception of internal/external from himself, difference that is more and more confused [11].

From other contributions, we can see how elderly uses increasingly simple define mechanisms in substitution of the complex ones [12]. These observations are useful for the caregiver to face up to the disease of the elderly and to handle the psycho-social changes of the disease [13]. 
Citation: Calabrese CM/Calabrese MC/Calabrese CM. The rehabilitation of the elderly in cognitive difficult: An integrated vision. Reality Orientation Therapy (R.O.T.) and the "caring" of relationship of diade elderly-care-giver. J Clin Psychiatry Cog Psychol 2018;2(2): $1-4$.

\section{R.O.T. Technique}

The reality orientation therapy is one of the most known and applied interventions in psycho-geriatrics to try to slow down the psycho-involution process, increasing the orientation skills towards the environment themselves and their life stories. The R.O.T. involves the administration of standardized cards with space-time questions with the aim of stimulating the elderly in a multi-modal way [5]. On the theoretical level in addition to cognitive theories about memory processes, the R.O.T. Technique reconnects mainly to cerebral plasticity of the elderly [5], namely that mental capacity that a person can use to compensate deficit or difficulties, activating different circuits from that normally used to perform certain activities. Other strength of this theory is that is can be used in dierent contexts, professional (nursing home, institutes, hospital etc.) and domestic (own home) by caregivers prepared to execute the "Informal R.O.T.".

R.O.T. technique has the aim of maintaining the cognitive connection with reality (space, time, personal identity) through continuous stimuli that the psychologist can create in the relationship with the elderly during the group session [3]. It is very important that the psychologist manages relationships with every elderly and that they create together a shared way, in which the elderly feels emotionally involved. One of the risks of this activity is that it becomes intricate and too generic, without following the needs of every elderly in the group.

The benefits of the R.O.T. have been widely confirmed by the scientific research, bringing improvement in the cognition and in behaviour of the elderly $[2,6]$. Generally, from interesting researches, we could see how the positive treatments like reality orientation, where at the base there is a multistimulation group therapy [14]. Based on Cognition, behaviour and motor operation or treatment in which the elderly is subjected a rehabilitation including task of cognitive training on performance of everyday activities [15]. There are significant and relevant effects of R.O.T. technique when it is combined with a pharmacological therapy, with donepezil administration [16]. R.O.T. technique must be performed consistently and without big time interruptions from a session to another one to keep satisfactory results.

In our center we believe in the ability of this technique to be used to keep a better reality exam for the elderly, but it must be integrated with other technique and a pharmacological therapy, to get a significant result.

Other techniques positively used are music therapy and occupational therapy. In the first case, music therapy involves benefits for the elderly, with a reduction of agitation and aggression [17]. Occupational therapy is a technique based on abilities [18]. They take on importance, in this regard, all the daily living abilities that with their progress can bring the elderly to a greater comprehension of social and psychic skills, through the body.

\section{Psychodynamic and Humanistic Contributions}

In the last decades much importance has been given to relationship between caregiver and elderly and to complexity of the person who lives dementia. The first contribution that signed this new trend has been given by Naomi Feil, theoretical of "Validation Therapy", giving more importance to psychological experience and to latent meaning of the behaviour of the elderly [19]. The skill of the psychologist is to succeed in establishing an emotional tuning with the elderly that manages to capture his emotional state, to have a partial self-awareness and so to reduce maladaptive and atypical behaviour.

We must keep in mind that elderly, during the course of the disease, lives the mourning of some parts of himself, lost capacities and abilities, but also information's connected with short and long term memory [20]. Caregiver and professionals, with a profound and meaningful relationship, can help the elderly accept and manage emotions connected with this lost, like stress, anxiety and anguish because of his physical and psychic decade. This work is very important because we think that reality orientation must be integrated with an intervention connected to emotively and affection felt by elderly.

Now we resume with the relationship between caregiver and elderly. The relationship that they live is very intense, because of the amount of time spent together, moments lived and sometimes enriched by affective elements. If caregiver is an elderly relative, often a work of acceptance and processing must be performed from the beginning, when diagnosis has just been made. Often the relative cannot understand all the emotions and the affection felt by the elderly, and also that their relationship is certainly influenced by a variety of conditions for example the style of attachment and the personality characteristics of the elderly and of the caregiver [21].

The need of work on the figure of the caregiver is clear, he lives in an indirect Way-out not in a less strong way. The moments of acute stress for caregiver are related to elderly crises, when he manifests hallucinations, wandering, reduction of daily activities and motor agitation [7]. People who assist an elderly, can live a strong ambivalence, often denied, connected with the desire for the death of the person, so a liberation, and with the desire of conservation of the loved one and so to take care of him.

Another problem that can derive from assistance is a significant change of caregiver moral sphere, mostly in the possibility of developing depression connected with caregiving [9]. The disease nature involves the creation of a strong relationship with who assists the elderly, so we must understand the relationship not only as a means for an intervention, also as a purpose to pursue: there are numerous witnesses in which psychological interventions based on psychotherapeutic elaboration of stress and depression factors improved the caregiver lived experience reactivating personal resources and a greater mastery of the situation [22]. Constant worries and frustrations can lead caregivers and elderly relatives to somatic and psychic disorders [23]. It is very 
important that caregiver does not identify himself only in his task; but that he understands and realizes his experiences and that he has a deep self-awareness, necessary to continue the care [24]. When it does not happen, the elderly affected by dementia can aggravate his symptoms, and there may be an increase of maladaptive behaviours, a greater abandonment of social norms and an alteration of interpersonal behaviour [25]. Another dangerous risk for the elderly is to develop depression. We are not yet aware of the true relation between depression and dementia, and if the first is a risk factor [26] or a part of the elderly symptomatology [27], anyway depressive phenomena leave traces of cognitive deterioration, also in the most atypical dementia forms, like pseudo-dementia.

It becomes important to take care of the caregiver and mostly of his suffering for his task. In addition to traditional approaches like psychological interview and psycho-therapies, in literature there are many studies about support group for caregivers [28]. Group is very useful for all its possible applications unlike traditional interventions in which it is necessary to respect certain criteria and setting. Support groups base their theoretical system on $\mathrm{K}$. Lewin studies, with is "Field Theory", but also Bion et al. who reconnecting the autobiographical narration of the subjects; claim the double role of the person who is a bearer and builder of shared meanings [29]. Other contributions are from inter-subjective psychoanalytic psychology, about the work that the person does on interpersonal internalized representation [30]. So the group can be used to satisfy the caregiver's need, the ones with an emotional and social nature, the information needs or with a relational nature [31]. It is important to have oneself story in the group, to broaden personal meaning and to know how to manage emotions. The narration of oneself becomes an essential tool for this people, and it is also very useful according to prospective like neurosciences, in which incarnated simulation and mirror neurons well represent the "biological meaning", of sharing [32-34].

In our center this type of intervention has been used for a long time with monthly meeting group, with a professional figure. We could ascertain the utility of this work, to give narration to them, and to their suering, to get free from dangerous and harmful to caregiver mental health experiences. This gives new strength to this people, to be able to go in their life.

\section{References}

1. Prince M, Comas-Herrera A, Knapp M, et al. World Alzhei-mer report 2016: Improving healthcare for people having with dementia. Alzheimer's disease International 2016.

2. Florenzano F. The reality Orientation in Psychogeriatrics. Rehabilitation techniques and cognitive evalution. Editrice Primerano 1988.

3. Guaita A, Vitali SF. Cognitive rehabilitation and training in the Alzheimer's disease: Facts and fantasies. G Gerontol. 2004;52:395-400.

4. Guaita A. Interventions on the disease and the patient: State of the art of "care". Alzherimer Ital. 2006;30.
5. Cotelli M, Calabria M, Zanetti O. Cognitive rehabilitation in early-stage Alzheimer's disease. G Gerontol. 2004;55.

6. Metitieri T, Zanetti O, Geroldi C, et al. Reality orientation therapy to delay outcomes of progression in patients with dementia. A retrospective study. Clinical Rehab. 2001;15:471-8.

7. Vellone E, Piras G, Sansoni J. Psychological aspects of the role of caregiver of patients with Alzheimer's disease: Between burden and empatia. Ann Ig. 2002;14.

8. Truzzi A, Valente L, Ulstein I, et al. Burnout in familial caregivers of patients with dementia. Rev Bras Psiquiatr. 2012;34:405-12.

9. Lucchetti L, Uhunwangho E, Esposito M, et al. The subjective load of caregivers of elderly people suffering from dementia: Which indications of intervention? Investigation in the Piacenza area. G Gerontol. 2007;55.

10. Vigorelli P. Communicating with the demented: From ineffective communication to happy conversation. G Gerontol. 2005;53:483-487.

11. https://pensiero.it/

12. Fassino S, Marozio S, Preda S, et al. For a psychodynamic approach in the clinic of senile dementia. Riv Psicol Indiv. 2006;60:93-110.

13. Gallese G, Stobbione T. Need-driven-dementiacompromised-behavior model and "gentle care" as answer to Alzheimer's disease. Prof Inferm. 2013;66:39-47.

14. Baglio F, Grialdi L, Saibene F, et al. Multistimulation group therapy in Alzheimer's disease promotes changes in brain functioning. Neurorehabil Neural Repair. 2015;29:13-24.

15. Kim S. Cognitive rehabilitation for elderly people with early-stage alzheimer's disease. J Phys Ther Sci. 2015;27:543-546.

16. Salotti P, de Sanctis B. Effectiveness of cognitive rehabilitation in mild Alzheimer disease: A case report. G Gerontol. 2012;60:182-187.

17. Villani D, Raglio A. Music therapy and dementia. G Gerontol. 2004;52:423-428.

18. Baldelli MV. Therapy of reactivation in geriatrics. FrancoAngeli 1991.

19. Feil N. Validation: The method Feil. Sperling \& Kupfer 1996.

20. Pavan F, Valdetarra P. Depression and Dementia. Psychology of the elderly. Centro scientifico Torinese. 1986.

21. Tognetti A. Le. Problems of the caregiver. G Gerontol. 2004;52:505-510

22. D'Anastasio, Ferriani E, Ciarrocchi R, et al. Demenzation: Quality of life and psychical health of the caregiver. G Gerontol 2012;60:99-105.

23. Spinnler H. Demential decay : Neurological and neuropsychological framing. Il pensiero scientifico 1985.

24. Lampasoda R, Giorgi A. Caregiving pathways: Analysis of a group experience of caregivers with dementia patients. Narrare i gruppi 2012;2. 
Citation: Calabrese CM/Calabrese MC/Calabrese CM. The rehabilitation of the elderly in cognitive difficult: An integrated vision. Reality Orientation Therapy (R.O.T.) and the "caring” of relationship of diade elderly-care-giver. J Clin Psychiatry Cog Psychol 2018;2(2): 1-4.

25. Poletti M. Deficit of social cognition processes in frontotemporal dementia: A cognitive basis for the disorder of interpersonal behavior and social behavior. Giornal. Ital di Psicologia. 2008;14.

26. Devanand DP, Sano M, Tang M, et al. Depressed mood and the incidence of Alzheimer's disease in the elderly living in the community. Arch Gen Psychiatry. 1996;53:175-82.

27. Chen $\mathrm{P}$, Ganguli M, Mulsant $\mathrm{BH}$, et al. The temporal relationship between depressive symptoms and dementia. Arch Gen Psychiatry. 1999;56:261-6.

28. Calabrese C, Aramini I, BAcigalupo P, et al. 1991. Center of cognitive reactivation in the territory of the XVIII USL ligure: Experiences and proposals for a treatment outcome evaluation. G Gerontol. 1991:39:11.

29. Taccani P, Giorgietti M, Landini F, et al. Care work and self-help: Groups for caregivers of non-self-sufficient elderly people. FrancoAngeli Editore. 2010.

30. Bruschetta S, Barone R, Frasca A. Research on Community Groups in Mental Health. FrancoAngeli. 2014.

31. Moroni L, Sguazzin C, Filipponi L, et al. Caregiver need Assessment: A questionnaire for caregiver demand. G Ital Med Lav Ergon. 2008;30:84-90.
32. Mastroianni A. Relational paintings and construction of the subject ego. FrancoAngeli. 2013.

33. Feuerstein R, Falik LH, Feuerstein RS, et al. Cognitive enhancement and rehabilitation of the elder population: application of the feuerstein instrumental enrichment program of the elderly. Life Span Disability. 2012:15:21-33.

34. Piana F. Psychological intervention in dementia: Humanistic and psychodynamic contributions. Psicoanalisi neofreudiana. 2013.

\section{*Correspondence to:}

\section{Calabrese Cesare Maria}

Punto R.O.T,

Center for prevention and support of the elderly in cognitive difficulties,

Italy

E-mail: cesare.calabrese@libero.it 